ANDRÉS GABRIEL VILLAMIZAR*

ILUSTRACIONES dE gEISON CASTAÑEdA

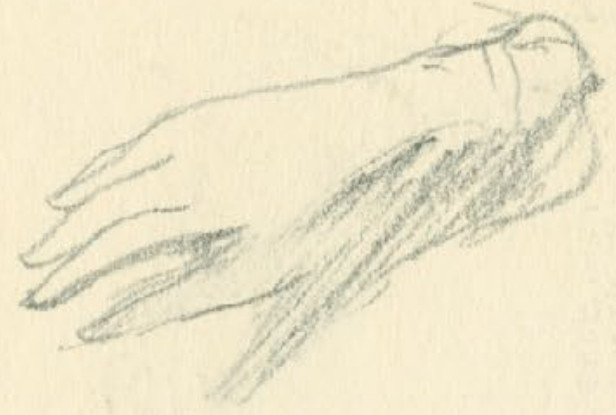

REFLEXIONES SOBRE UNA INVESTIGACIÓN ACERCA DEL ALFABETISMO VISUAL:

\title{
EL PAPEL DE LA
}

IMAGEN EN LA 


\section{REFLECTIONS FROM A STUDY ON VISUAL LITERACY: THE ROLE OF THE IMAGE IN ADULT EDUCATION}

Fecha de recepción: 8 de mayo de 2018

Fecha de aceptación: 17 de septiembre de 2018

Sugerencia de citación: Villamizar, Andrés Gabriel. 2020. Reflexiones sobre una investigación acerca del alfabetismo visual: El papel de la imagen en la educación adulta. La Tadeo Dearte 6(6), 92-117. doi: 10.21789/24223158.1417

* Licenciado en arquitectura de la Pontificia Universidad Javeriana, Licenciado en ArtesVisuales, Monash University, Magíster en Educación con énfasis en docencia de la lengua inglesa, Monash University, Posgrado en Educación Secundaria con especialización en docencia de la lengua castellana y artes visuales, Australian Catholic University. Actualmente cursando Doctorado (PhD) en la Facultad de Educación de Monash University

Profesor asociado de Monash University y RMIT University (Royal Melbourne Institute of Technology), Australia.

https://orcid.org/0000-0002-6190-501X

andres.villamizar@monash.edu 
TRADICIONALMENTE, la imagen ha sido considerada útil en la enseñanza de lenguas. Hoy, educadores alrededor del mundo superan barreras culturales gracias a Google, YouTube, iPhones, cómics y muchas otras plataformas, a través de las cuales las fotografías, las ilustraciones y los videos contribuyen a darle significado a las palabras. Este artículo expone reflexiones originadas en mi estudio doctoral sobre la conceptualización de la alfabetización visual en la enseñanza del inglés para adultos. Se investiga qué entienden los profesores participantes como alfabetismo visual, el papel que le atribuyen a la imagen en sus pedagogías y los diferentes usos que le dan, basados en sus principios y experiencias. Los resultados indican que el uso de la imagen como soporte al texto escrito limita su validez como medio de comunicación en sí, relegándola a una posición secundaria. Al parecer, en esta área de la educación se enseña «con imágenes» y no «sobre imágenes».

\section{RESUMEN/ABSTRACT}

TRADITIONALLY, the image has been considered a useful tool in language teaching. Today, educators worldwide overcome cultural barriers thanks to Google, YouTube, picture books, iPhones, cartoons and many other platforms. Through these, photographs, illustrations and videos contribute to making meaning from words. This article presents reflections emerging from my doctoral study about conceptualizations of visual literacy in adult English language teaching. It enquires into what the participating teachers understand as visual literacy, the role they assign to images in their pedagogies and their rationale to employ them, based on their beliefs and experiences. Findings suggest that the use of images as complementary to written texts limits their legitimacy as a communication medium and places them in a subordinate position. The common practice in adult English language classrooms appears to be teaching "through images" rather than "about images". 
$\mathbf{U}_{\circ}^{\infty}$
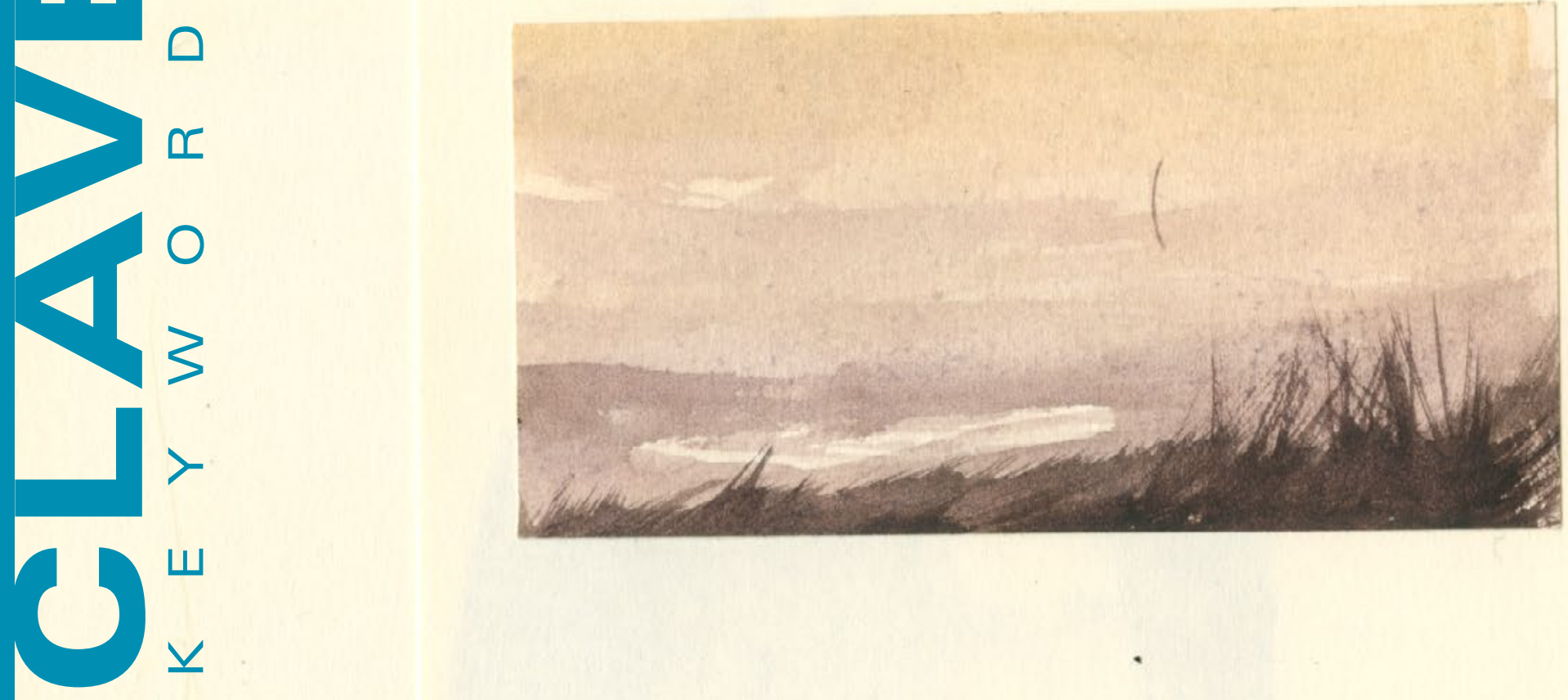

ALFABETIZACIÓN VISUAL / EDUCACIÓN ADULTA / METODOLOGÍAS DE ENSEÑANZA / ENSEÑANZA DE INGLÉS / LA IMAGEN COMO MEDIO DE COMUNICACIÓN

VISUAL LITERACY / ADULT EDUCATION / TEACHING METHODOLOGIES / ENGLISH LANGUAGE TEACHING / THE IMAGE AS A COMMUNICATION MEDIUM 


\section{INTRODUCCIÓN}

EN UN MUNDO en el que la mayoría de la información se presenta en gran medida en forma visual (Donaghy and Xerri 2017), no es extraño que la imagen (llámese pintura, fotografía, video, emoji o gesto corporal) sea considerada esencial para convivir, entender, aprender y trabajar en una sociedad contemporánea (Kress and van Leewen 2006, de Silva Joyce 2014, Keddie 2014). Consecuentemente, las definiciones del concepto de «alfabetismo» han evolucionado considerablemente desde que este era visto simplemente como «la capacidad de leer y escribir» (Goody 1999, 29). Las interpretaciones modernas de este término incorporan la habilidad de captar información y la de comunicarse en forma oral y escrita, además del uso efectivo de imágenes, sonidos y una diversidad de nuevas tecnologías, entre otras (Lankshear 2003, Kress and van Leewen 2006, Kalantzis and Cope 2000, Nixon and Kerin 2012).

Precisamente, debido al surgimiento de innumerables formas de expresión de nuestra capacidad intelectual, hoy en día la noción de alfabetismo se expande a muchos contextos y disciplinas. Este artículo concierne al concepto de «alfabetismo visual» y sus implicaciones en la enseñanza de inglés para adultos. Mi interés en este tema se origina en una amalgamación de experiencias de vida personales y profesionales. Estas incluyen mis estudios de arquitectura en la Universidad Javeriana de Bogotá, y Artes Visuales y Educación en la Universidad Monash (en Melbourne, Australia), así como mi investigación doctoral (también en Monash). Mi trabajo como profesor e investigador de los idiomas inglés y español en varias universidades y centros de educación adulta en Melbourne durante los últimos 13 años proporcionan el contexto. 


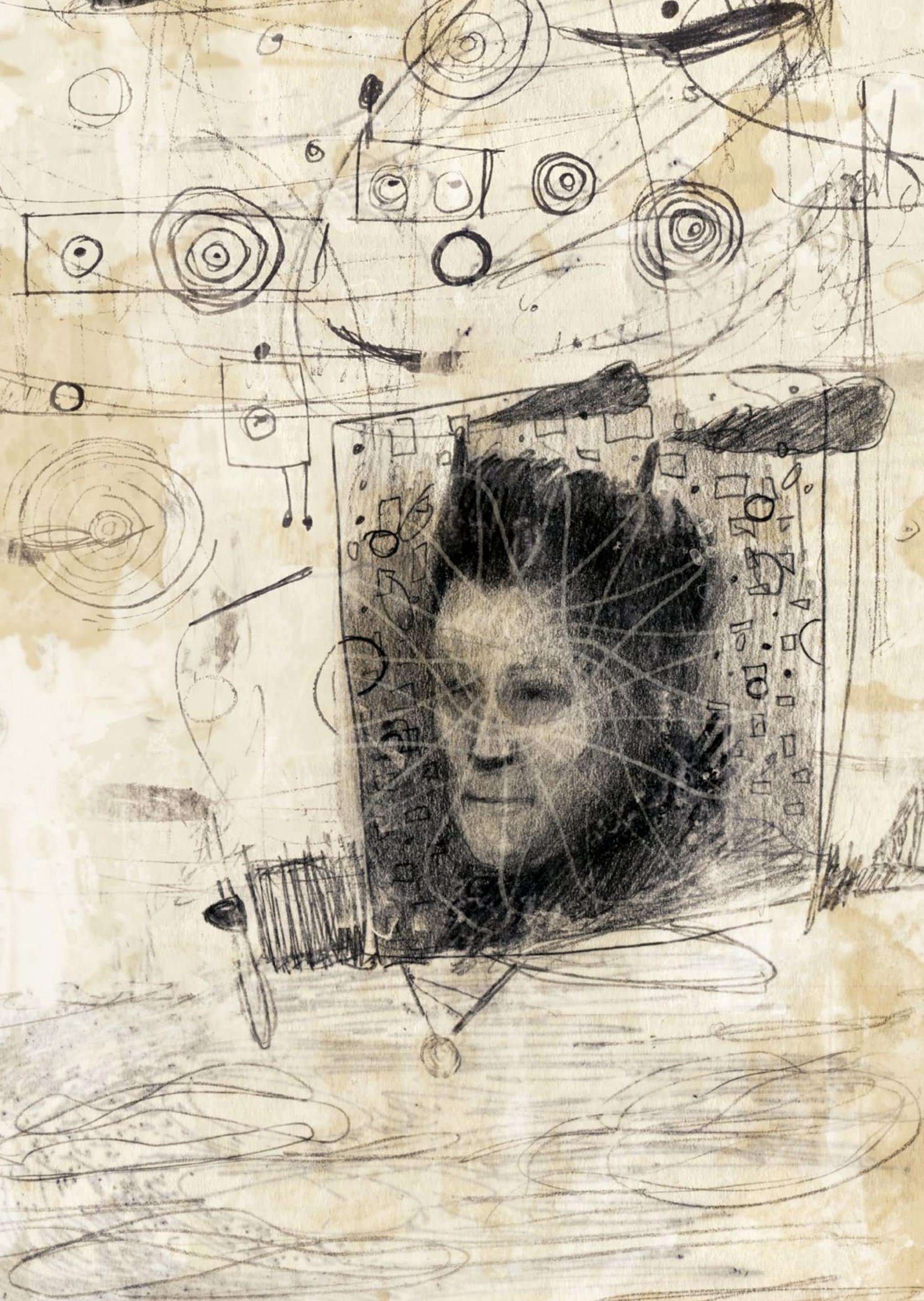




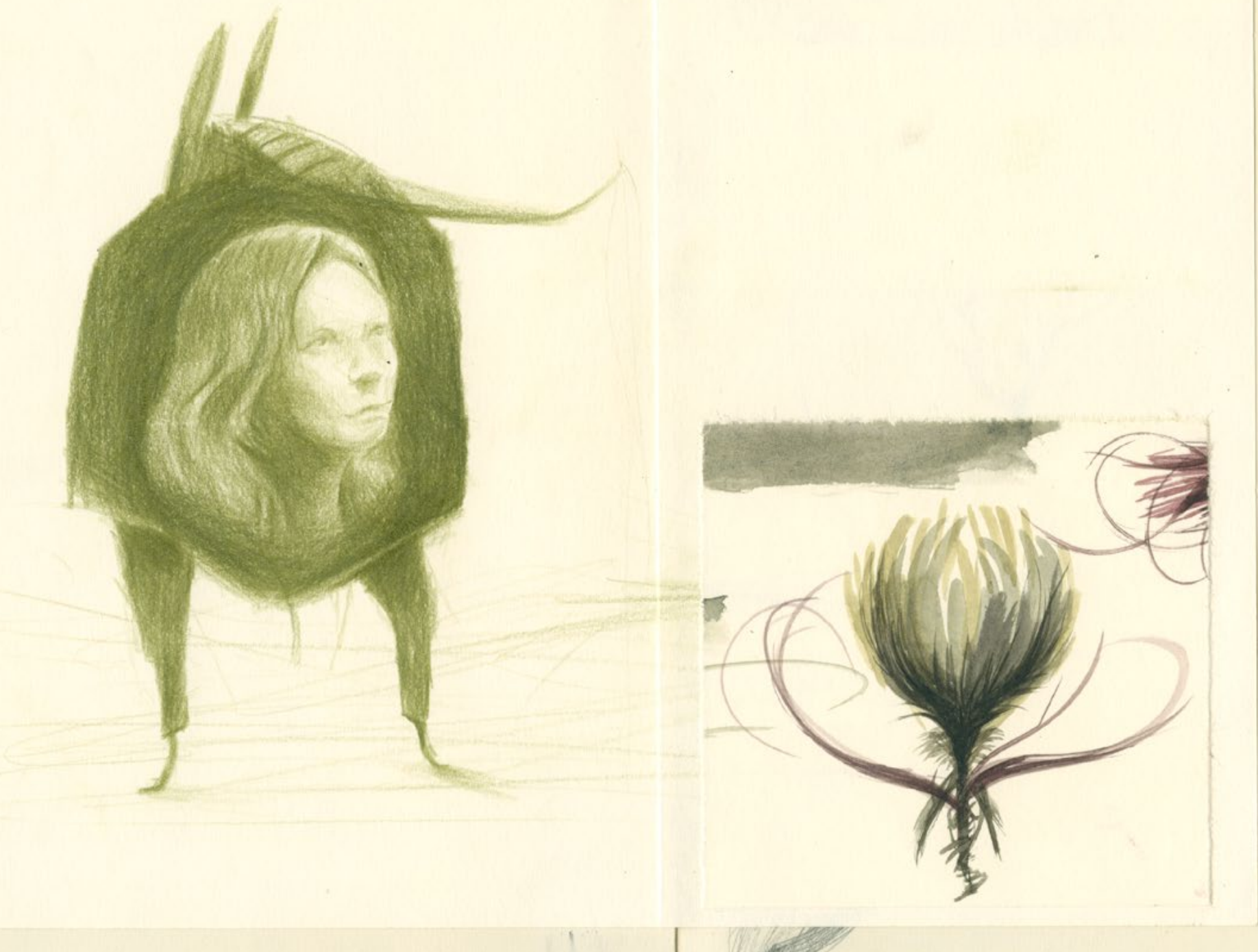

\section{ALFABETISMO VISUAL}

A PESAR de que los catedráticos Peña y Dobson (2016) de la Universidad de British Columbia en Vancouver, Canadá, condujeron una investigación exhaustiva que comprueba la existencia y uso del término visual literacy (alfabetismo visual) desde 1939, John Debes (1969), fundador de la Asociación Internacional para el Alfabetismo Visual (IVLA, por sus siglas en inglés The International Visual Literacy Association), es generalmente reconocido como pionero en su acuñación. John Debes hace énfasis en los medios de comunicación del alfabetismo visual, los cuales lo hacen diferente a los procesos de escribir o hablar, en los que se utilizan letras o fonemas para formar palabras:

Visual literacy is a group of vision-competencies a human being can develop by seeing and at the same time having and integrating other sensory experiences. The development of these competencies is fundamental to normal human learning. When developed, they enable a visually literate person to discriminate and interpret the visible actions, objects, symbols, natural or man-made, that he encounters in his environment. Through the creative use of these competencies, he is able to communicate with others. Through the appreciative use of these competencies, he is able to comprehend and enjoy the masterworks of visual communication.

El alfabetismo visual es un conjunto de habilidades relacionadas con el sentido de la vista, las que el ser humano adquiere a través de la visión y otras experiencias sensoriales. El perfeccionamiento de estas habilidades es fundamental para el aprendizaje. Cuando se desarrollan, éstas le permiten al alfabetizado visual discernir e interpretar las acciones visibles, objetos, símbolos (naturales o creados por el hombre) que él encuentra en su contexto. Mediante el uso creativo de dichas habilidades le es posible comunicarse con otros, así como apreciar y entender las obras maestras de la comunicación visual (26). 
Este parece haber sido el punto de partida de muchas otras definiciones propuestas durante las últimas cinco décadas. Avgerinou (2001), una investigadora contemporánea del campo, define el alfabetismo visual como «las habilidades de entender (leer) y usar (componer) imágenes, así como la capacidad de pensar y aprender en términos de imágenes» (26). Con el fin de enmarcar la discusión en este artículo, me adhiero a la explicación que ofrece la Asociación de Bibliotecas de Colegios e Investigación (ACRL - por sus siglas en inglés the Association of College and Research Libraries). De acuerdo a los Estándares de competencias en alfabetismo visual para educación universitaria (2011) propuestos por la $A C R L$, un individuo que posee alfabetismo visual posee la capacidad de:

- Determinar la naturaleza y alcance de los materiales visuales

- Identificar y acceder imágenes y medios visuales de manera efectiva y eficiente.

- Interpretar y analizar los significados de imágenes y medios visuales.
- Evaluar imágenes y su procedencia.

- Emplear imágenes y medios visuales eficientemente.

- Diseñar y crear imágenes y medios visuales que tengan sentido.

- Entender los problemas éticos, legales, sociales y económicos que rodean la creación y uso de imágenes y medios visuales, así como su acceso y uso ético (Association of College and Research Libraries (ACRL) 2011, 1).

La decisión de adherirme a los estándares de la ACRL no fue arbitraria. Con el propósito de la revisión bibliográfica para mi tesis doctoral, identifiqué una plétora de literatura sobre alfabetismo visual. No obstante, gran parte de los estudios que exploran y aplican el término en Australia se llevan a cabo en el ámbito de escuela primaria y secundaria (Atkins 2006, Barton 2016, Bennett 2011, Callow 2007). Debido a que el contexto de mi investigación es específicamente en la educación adulta, estándares concebidos como línea de base para estudiantes de universidad y no para niños o adolescentes indican ser los más aptos.

\section{ENSEÑANZA dE INGLÉS PARA AdULtos}

LA ENSEÑANZA de inglés para adultos es un sector boyante de la educación global, la cual se expande día a día como consecuencia de la necesidad de una lingua franca que nos sirva como medio de comunicación común y rompa barreras políticas, económicas y socioculturales (Sharifian 2013). En Australia, el constante movimiento de inmigrantes provenientes de todo el mundo y el número creciente de estudiantes extranjeros que pueblan las universidades han generado una enorme industria (English Australia 2015, Bundensen 2011). Esta industria se divide en dos sectores, los cuales proveen, por una parte, programas de asentamiento y alfabetización para inmigrantes y refugiados adultos, y, por otra, cursos pre-universitarios para aquellos estudiantes extranjeros cuyo inglés necesita ser reforzado antes de empezar sus programas de pregrado, maestrías o de investigación (Carey and Robertson 2015, Rizvi 2011, English Australia 2015).
Los programas para inmigrantes y refugiados buscan proporcionarles las herramientas comunicativas necesarias para incorporarse a dicha sociedad como participantes activos, quienes finalmente ingresarán al mercado laboral (Martin 2000). Mientras tanto, los cursos pre-universitarios se enfocan en equipar a sus estudiantes con el nivel académico de inglés necesario para su disciplina escogida (ELICOS 2014, Australian Education International 2011). Lo que tienen en común estas dos áreas es que aun cuando investigadores defienden la inmediata necesidad de poderse comunicar a través de imágenes (Kalantzis and Cope 2014, Kress and van Leewen 2006, Messaris 2012, Avgerinou 2007, Callow 2007), la prioridad de los establecimientos que ofrecen dichos programas y de los educadores que los enseñan continua siendo el perfeccionamiento de las habilidades de lectura, escritura y dicción. Mi pregunta entonces es ¿qué papel tiene la imagen en la enseñanza de inglés para adultos? 


\section{VALIDEZ}
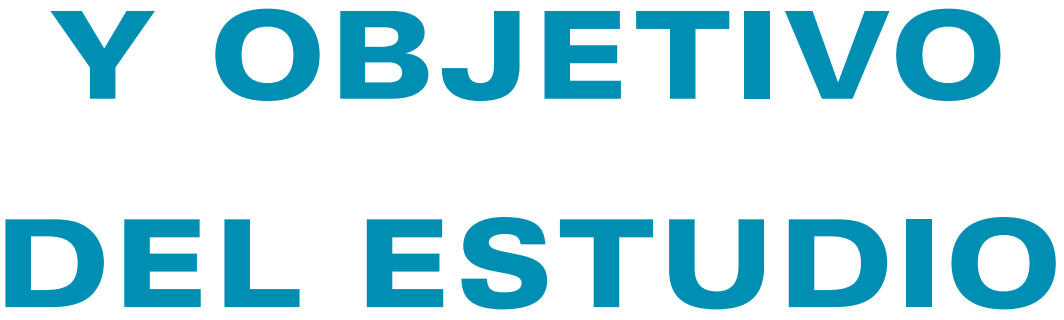

LA IMPORTANCIA del alfabetismo visual en el campo de la educación es aceptada ampliamente. Investigadores, educadores y diseñadores de currículo comparten la opinión de que las habilidades de interpretar imágenes en forma crítica y comunicarse en forma visual son imprescindibles hoy en día (Donaghy and Xerri 2017). Partiendo de este principio, esta investigación denuncia la necesidad de un estudio que examine el concepto de alfabetismo visual en el sector adulto de la educación, específicamente desde el punto de vista del docente. Mi objetivo principal es el de contribuir al conocimiento que los profesores de inglés para adultos poseemos en cuanto al papel que cumple la imagen en nuestras pedagogías. Necesitamos mayor claridad sobre cómo podemos capitalizar las interconexiones que existen entre el alfabetismo visual y las habilidades que históricamente se han considerado el objetivo del proceso de alfabetización y características de una persona alfabetizada -leer, escribir y hablar correctamente-.

Aunque esta investigación se llevó a cabo en Melbourne, Australia, espero que las ideas generadas se puedan aplicar al mejoramiento en el diseño de currículo y pedagogías en cualquier contexto geográfico, no solo en al área de cursos de inglés para adultos, sino también en programas de preparación de profesores de lenguas. 


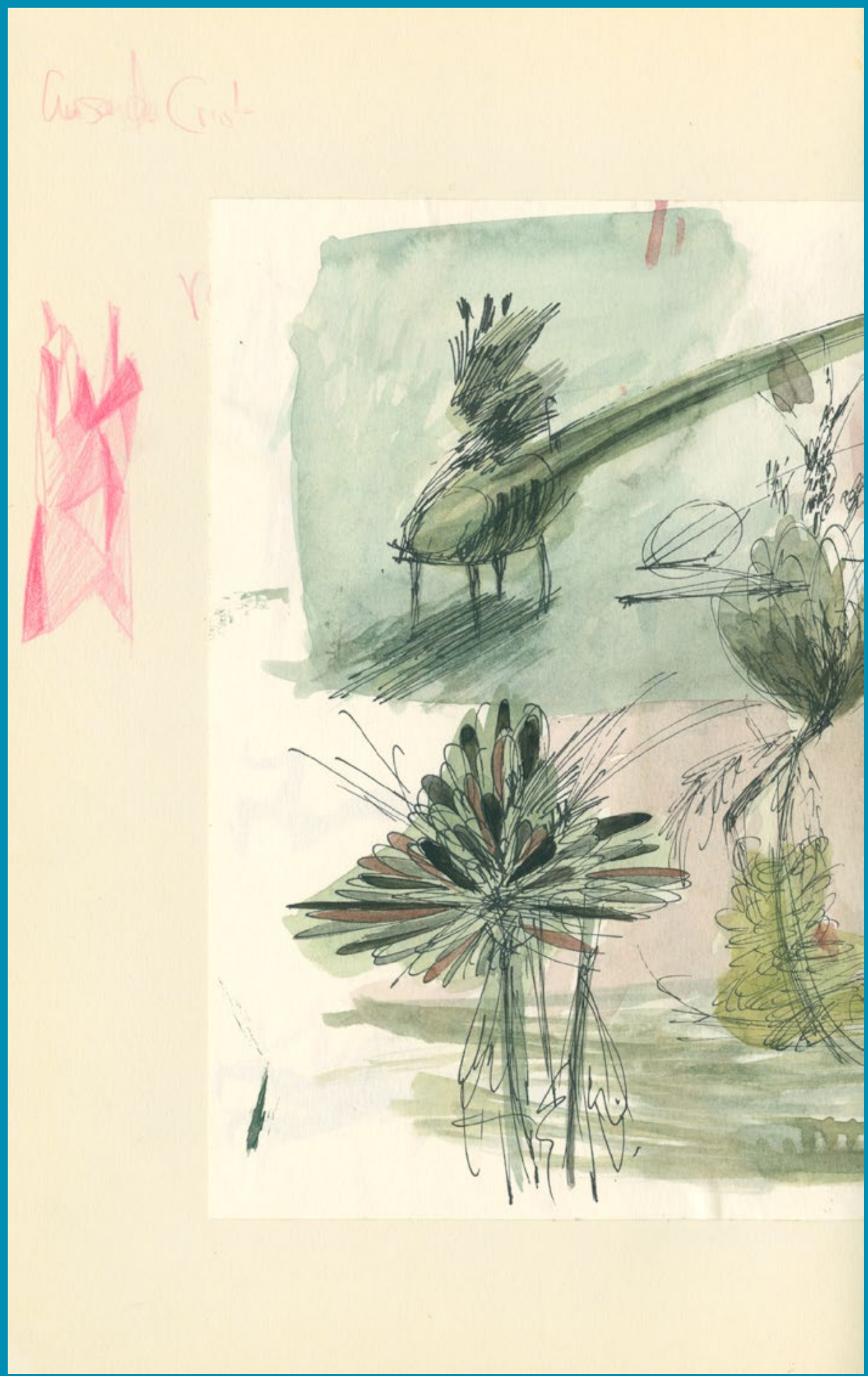




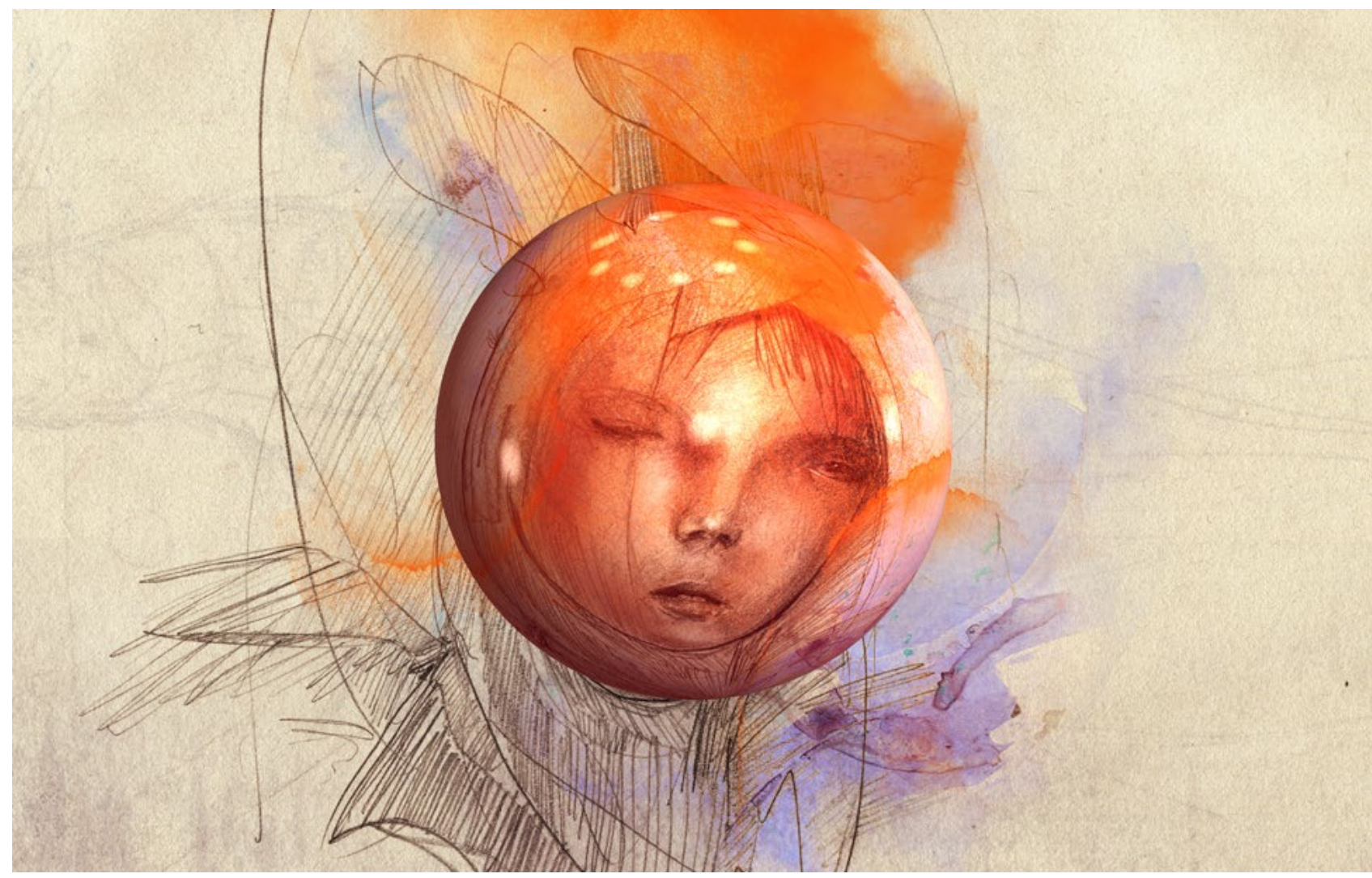

\section{MARCO TEÓRICO:}

\section{ESTUDIOS CULTURALES}

KEDDIE (2014), educador, escritor, facilitador, videógrafo y experto en redes sociales, contradice la idea de que una imagen narra una historia. Por el contrario, él sugiere que los seres humanos, quienes observamos una fotografía, una animación, un gesto facial, una caricatura, una página web o un video (entre muchas otras formas de expresión visual), somos los que creamos nuestras propias historias, las cuales son únicas y personales. Esta observación representa un principio relevante para identificar el marco teórico que pudiese guiar este estudio sobre alfabetismo visual: la noción de que el significado que le damos a las imágenes es enormemente influenciado por el ambiente que habitamos, que, junto a nuestras experiencias de vida, forman la cultura en la que dichas imágenes existen.

El campo de investigación llamado Estudios Culturales se interesa en los principios, valores, creencias, costumbres y comportamientos que forman los pilares de una sociedad (incluyendo su lengua, actos religiosos, tradiciones familiares, etc.) (Hall 1990, Hoggart 1969). Según Stuart Hall (1980, 1990, 1996), uno de los principales referentes de los Estudios Culturales, la cultura está cimentada en la interpretación crítica que sus participantes le dan a los fenómenos que ocurren a su alrededor (expresados con palabras, sonidos, imágenes y otras formas de comunicación), y de su producción e intercambio de ideologías diversas y comunes sobre el mundo que habitan. Desde este punto de vista, la imagen no es la simple representación visual de la palabra, sino un elemento esencial de la cultura que define a una sociedad. En este estudio, la imagen es entonces entendida no como auxiliar a la lengua escrita, sino como un medio de representación - una lengua en sí. Además, así como otros medios de representación como la lengua escrita, no es neutral ni estática, la comunicación a través de la imagen fluye, cambia y origina diversos significados, dependiendo de la cultura. 


\section{MÉTODOS Y ANÁLISIS}

ESTA INVESTIGACıón cualitativa de índole descriptivo y exploratorio se condujo en cinco centros de docencia de inglés en el área metropolitana de Melbourne, Australia. Tres de ellos son dedicados a enseñar a adultos que han ingresado al país en calidad de inmigrantes permanentes o con visa de refugiados. Los otros dos pertenecen a universidades y se encargan de preparar a sus estudiantes para cursos de pre y posgrado. Un total de 15 profesores (dos hombres y 13 mujeres) participaron en el estudio. Todos poseen títulos de docencia en inglés y experiencia docente que varía entre dos y treinta años.

La metodología seguida se adhiere a los principios de «estudio de caso» o «estudio monográfico» (Yin 2009, Hyett, Kenny, and Dickson-Swift 2014). La validez de un estudio de caso se basa en la profundidad con que se investigan los datos, y no la cantidad de estos, como ocurre en los estudios cuantitativos. A raíz de esto, en el estudio de caso un análisis estadístico no es imperativo. Lo que sí es fundamental es que tanto el investigador como el consumidor tengan claro que el análisis que se lleva a cabo es profundo, subjetivo y flexible. Este tipo de investigación se basa en descripciones detalladas del contexto, el fenómeno y/o la persona que se estudia, y en un análisis de datos que busca identificar temas comunes, patrones de comportamiento o problemas destacados (Wolcott 1994, Stake 1995).

El objetivo primordial del caso de estudio cualitativo no es el de comprobar una hipótesis sobre una población general (en este caso de profesores de inglés para adultos) mediante resultados comunes en una extensa muestra. Por el contrario, el investigador en un caso de estudio busca generar teorías a partir de su análisis íntimo de los resultados, para así entender mejor un fenómeno y cuestionar si dichas teorías se pueden aplicar en un área de interés específico (Yin 2009).
Para obtener información válida sobre las ideas de los participantes con relación al alfabetismo visual y la imagen en su área profesional, se condujeron entrevistas semiestructuradas de una hora de duración con cada uno de los profesores y dos grupos de discusión (también de una hora). El objetivo de las entrevistas individuales fue el de entender sus ideas y preconcepciones que tienen los participantes sobre el concepto de alfabetismo visual y qué importancia le conceden a este en sus prácticas de enseñanza-aprendizaje del inglés para adultos; además, con qué propósitos usan las imágenes en sus metodologías. Los grupos de discusión fueron clave para observar en la práctica cómo los participantes relacionan conceptos específicos con su selección de imágenes y hasta qué punto esta es influenciada por sus experiencias como educadores y otros factores como su formación profesional y el medio en el que enseñan.

Se llevó a cabo un análisis temático de las transcripciones de las entrevistas y los grupos de discusión. Este análisis se enfocó en el contenido de dichas interacciones, mas no en el aspecto lingüístico, pragmático o discursivo de las conversaciones. El análisis temático funcionó en este caso como una herramienta válida de investigación que por su carácter flexible y no prescriptivo contribuyó a formar una descripción compleja de los datos obtenidos. Siguiendo las directrices del análisis temático sugeridas por Braun and Clarke (2006) se cumplieron los siguientes procesos: 1) Familiarización con los datos; 2) Creación de códigos iniciales generales (estos surgieron de los datos y no fueron prefabricados); 3) Identificación de temas comunes en dichos códigos y generación de categorías amplias; 4) Revisión de dichas categorías a temas más específicos; 5) Catalogación de los temas para generar tópicos de discusión; y 6) Compilación de tópicos de discusión y producción de un reporte de resultados que funcionó como base de la discusión. 
$\stackrel{\infty}{\frac{\alpha}{3}-}$

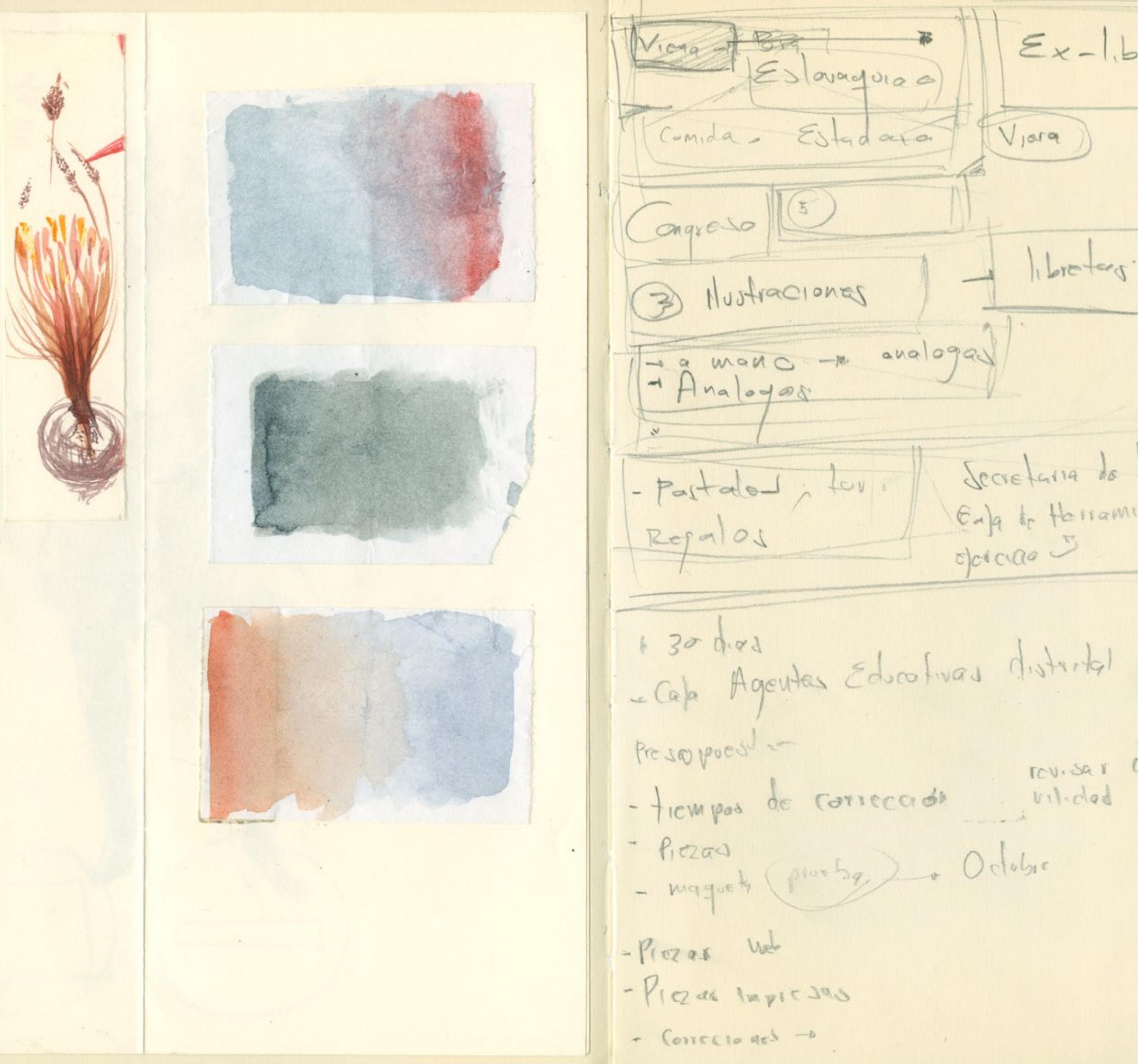


LOS RESULTADOS se presentan a continuación en relación a tres temas centrales: primero, las conceptualizaciones de los participantes sobre el alfabetismo visual en el contexto de enseñanza de inglés para adultos; segundo, sus creencias sobre el papel de la imagen en su labor como docentes; y tercero, la influencia de su formación profesional en sus ideas y prácticas pedagógicas. 


\section{CONCEPTUALIZACIONES SOBRE}

\section{EL ALFABETISMO VISUAL EN LA}

\section{ENSEÑANZA DE INGLÉS PARA ADULTOS}

CON EL OBJetivo de introducir el tema del alfabetismo visual durante las entrevistas, primero se exploró la idea fundacional del alfabetismo. Ocho de los quince participantes explicaron el concepto en simples términos: «la habilidad de leer y escribir». Esta definición es congruente con ideas tradicionales sobre la enseñanza de lenguas, la cual, como se discutió anteriormente, le da prioridad al desarrollo de la lectura y la escritura. Este punto de vista se alinea con el de Goldstein (2008), quien argumenta que la idea del alfabetismo usualmente concierne a la capacidad y eficiencia con las que el estudiante maneja los sistemas de la lengua oral y escrita, con sus unidades lingüísticas - las letras y los sonidos-que conducen a entender el significado de las palabras.

Las respuestas de los otros siete participantes incorporaron las ideas de «entender» y la de "construcción de significado» en sus definiciones de alfabetismo. En estas tuvieron en cuenta que sus pupilos poseían experiencias de vida y educativas que ocurrieron en diversos ámbitos socioculturales y que influyen en la interpretación que cada individuo le asigna a las letras y los símbolos.

Ya habiendo establecido un punto de partida - alfabetismo-, las entrevistas se enfocaron en el alfabetismo visual. La primera idea que surgió en las conversaciones fue que alfabetismo visual es la habilidad de «leer imágenes» y darles sentido. Georgie, por ejemplo, explica:

\footnotetext{
El alfabetismo visual es la habilidad de leer e interpretar cualquier cosa que puedes ver pero que no son palabras. Tal vez colores y formas, más comúnmente en fotos, gráficas y diagramas, y darle significado a estos (Georgie, entrevista 2).
}

Los autores Kress y van Leewen (2006) han explorado esta idea de leer imágenes, definiéndola como la habilidad de una persona de examinar los elementos estéticos (color, luz, medio, técnica) y las estructuras de diseño (composición, perspectiva) presentes en cualquier imagen. Messaris (2012) explica que este procedimiento de decodificación de imágenes es equivalente al proceso por el cual un lector descifra símbolos para darle sentido a palabras y frases.

Otros participantes añadieron a su explicación de alfabetismo visual que este además de incluir la lectura de imágenes requiere que el observador produzca una respuesta oral o escrita.

El alfabetismo visual es la habilidad de traducir fotografías y gráficas a palabras. Probablemente también entenderlas y ser capaz de transformarlas a palabras en una presentación oral (Kylie, entrevista 4).

Desde este punto de vista, el alfabetismo visual tiene dos direcciones: el consumo de información y la producción o codificación de una respuesta. Cabe notar que aquí la imagen es considerada un estímulo para generar una reacción oral o escrita.

La idea de cultura se configuró en forma prominente en las conceptualizaciones de alfabetismo visual presentadas. Tres de los participantes sugirieron que la habilidad de interpretar una imagen no solo depende de la cultura en la que se observa, sino que también es fundamental para entender dicha cultura. A continuación se ilustra esta idea a través de la respuesta de uno de los participantes (un profesor australiano, hablante nativo de inglés).

Estaba enseñando inglés en China cuando se me ocurrió utilizar una imagen de una pareja que estaba desayunando. No era una foto obscena ni nada, estaban en pijama. Sin embargo, la reacción de mis estudiantes me causó gran preocupación. Ellos se reían y se decían cosas al oído. Así que me fui a buscar a otra profesora, que era china, y le pregunté qué problema tenía mi imagen. Ella la observó detenidamente y me dijo que como ellos estaban sentados a la mesa y no tenían zapatos, esto indicaba que acababan de hacer el amor (Julián, entrevista 13). 

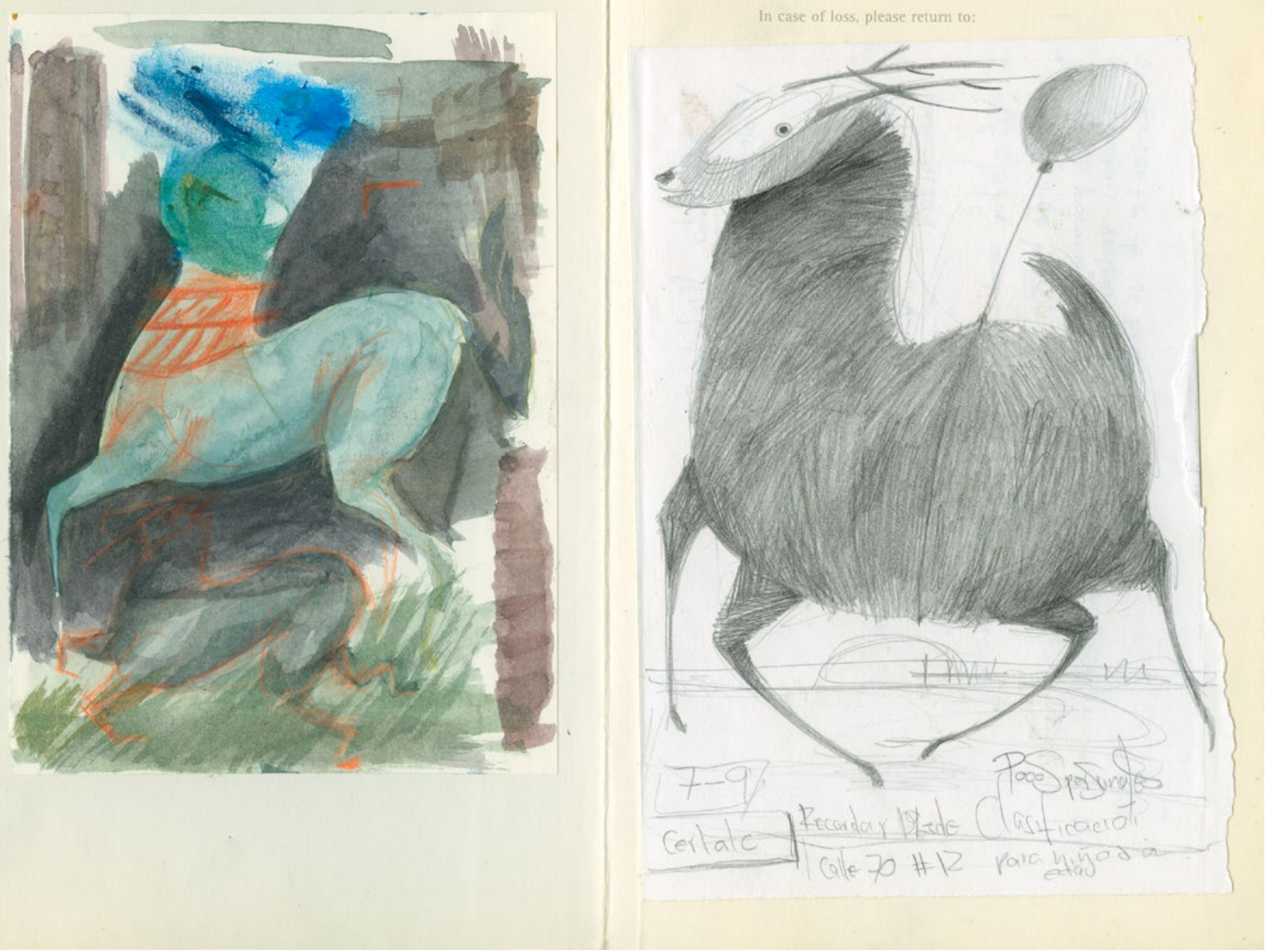

Esta historia demuestra en forma contundente la importancia de entender y facilitar el alfabetismo visual. De aquí se pueden derivar varias conclusiones. En primer lugar, que efectivamente una imagen no tiene un significado. Por el contrario, la interpretación que se le dé depende del contexto cultural. Segundo, que dos personas nunca formularán exactamente la misma interpretación. Finalmente, que uno de los aspectos más significativos del alfabetismo visual es la de poder evaluar en forma reflexiva el significado de una imagen en cuanto a su contexto, de manera que esa facilite la comunicación. En este caso en particular dos elementos causaron choque cultural: el profesor ignoraba la connotación sexual de la imagen «inocente» que había seleccionado, y los estudiantes la interpretaron basados en las normas y creencias populares de la cultura de su país.

Finalmente, una idea que surgió pero que solo fue abordada por un participante, fue el reconocimiento del alfabetismo visual como un proceso de comunicación bilateral a través de la imagen:

Para mí el alfabetismo visual sería cuando uno mira imágenes y comunica su respuesta a través de imágenes también (Muriel, entrevista 14).

Esta perspectiva considera al observador como el agente que protagoniza un proceso de dos direcciones, en el que interpreta el significado que una imagen tenga para él o ella y formula una respuesta visual y no en palabras. Un ejemplo que puede ilustrar esta idea es cuando una tarea requiere que el estudiante de inglés analice una gráfica, y en lugar de pedirle que escriba o diga algo sobre lo que entiende, este debe producir otra representación visual, como una fotografía, una ilustración, un emoji o incluso a través de gestos faciales. Este proceso, por supuesto, es mucho más complejo que el de traducir palabras a imágenes, pero es esencial en un mundo en el que la comunicación ya no ocurre simplemente a través de textos orales o escritos, sino multimodales, los cuales usan simultáneamente palabras, sonido, movimiento, olor y muchas otras formas sensoriales y tecnologías (Walsh 2010, Oskoz and Elola 2016, Boche and Henning 2015). 

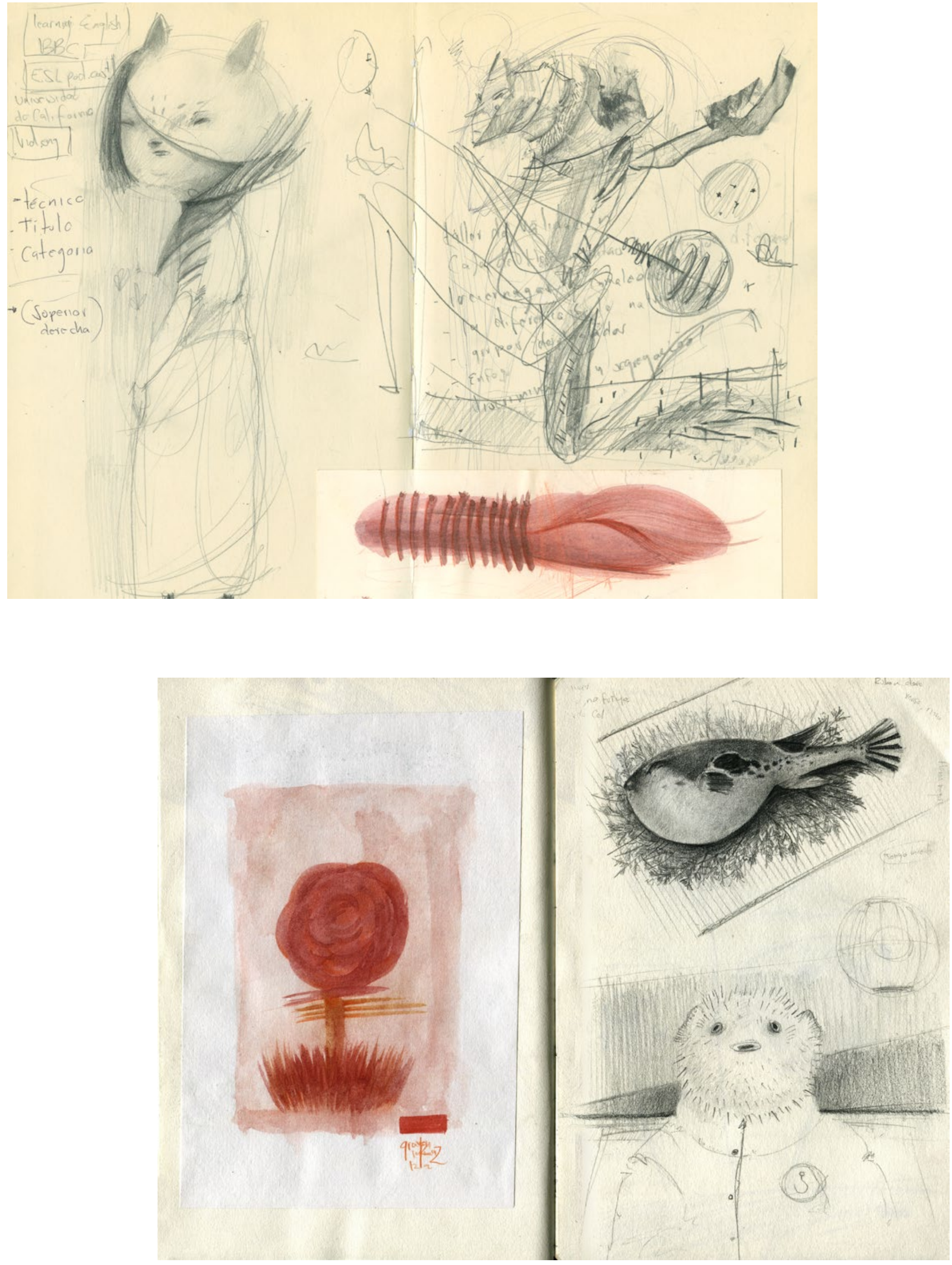


\section{CREENCIAS SOBRE EL PAPEL DE LA IMAGEN EN LA LABOR DEL DOCENTE}

ESTA SECCIÓN explora de qué manera las conceptualizaciones de alfabetismo visual formuladas por los participantes se reflejan en sus pedagogías y examina el papel que como profesores de inglés para adultos le asignan a la imagen. La idea central que se destaca en los datos obtenidos a través de las entrevistas y los grupos de discusión es que los educadores ven la imagen principalmente como soporte de los textos escritos y orales, y no como un medio de comunicación en sí que requiere instrucción y la atención misma que se le dedica a las palabras. Los siguientes extractos demuestran esta conclusión:

Si los estudiantes no pueden escribir o leer, entonces las imágenes se convierten en nuestro recurso principal para comunicarnos con ellos, porque si su lengua es limitada, entonces tenemos que usar imágenes para facilitar el aprendizaje y que nos entiendan (Alegra, entrevista 1).

En nuestro contexto de docencia de inglés creo que las imágenes se pueden usar como un medio introductorio antes de enseñarles a leer y escribir. Puede ser algo más fácil de digerir, como una prueba... Dejarlos intentar un poco, por medio de la observación porque es más fácil para el cerebro, para los ojos y para la persona (Winnifred, entrevista 6).

Si ellos pueden ver una imagen entonces pueden generar algo de lenguaje, porque la imagen puede recordarles previas experiencias. Hoy, por ejemplo usé imágenes todo el día y los estudiantes lograron escribir un párrafo sobre lo que les mostré (Jenny, entrevista 12).
En cualquier situación en la que enseño niveles básicos uso una cantidad de imágenes. ¡Hasta dibujo! Hago cualquier cosa para ayudarles a entender mi mensaje. No creo que podría enseñar si mis estudiantes no tuvieran la oportunidad de ver una imagen. Esta puede usarse para iniciar una conversación o para reforzar algo que se les ha enseñado (Lili, entrevista 7).

Estos testimonios generan varios puntos de discusión. Primero, ejemplifican el papel preliminar, secundario o de soporte que al parecer se le da a la imagen. La visión de que esta ayuda a fomentar la lectura y escritura de palabras y de que facilita la producción oral coincide con conceptualizaciones de alfabetismo visual como la habilidad de interpretar una fotografía, un video o una gráfica y explicarlos en forma oral o escrita. También se indica que los educadores consideran que el consumo de imágenes es un proceso mucho más simple o fácil que el de leer. Por lo tanto, en ocasiones, una ilustración o un video se usa como último recurso pedagógico, o de salvación o «relleno». Finalmente, la imagen es considerada como un detonador de memorias que los estudiantes pueden utilizar como punto de referencia, y los profesores como herramienta para la construcción de lengua oral o escrita. Este último punto es coherente con la idea explorada en la sección anterior de que la imagen esta intrínsecamente conectada a la cultura de la persona que la observa y en la que dicha imagen existe. 


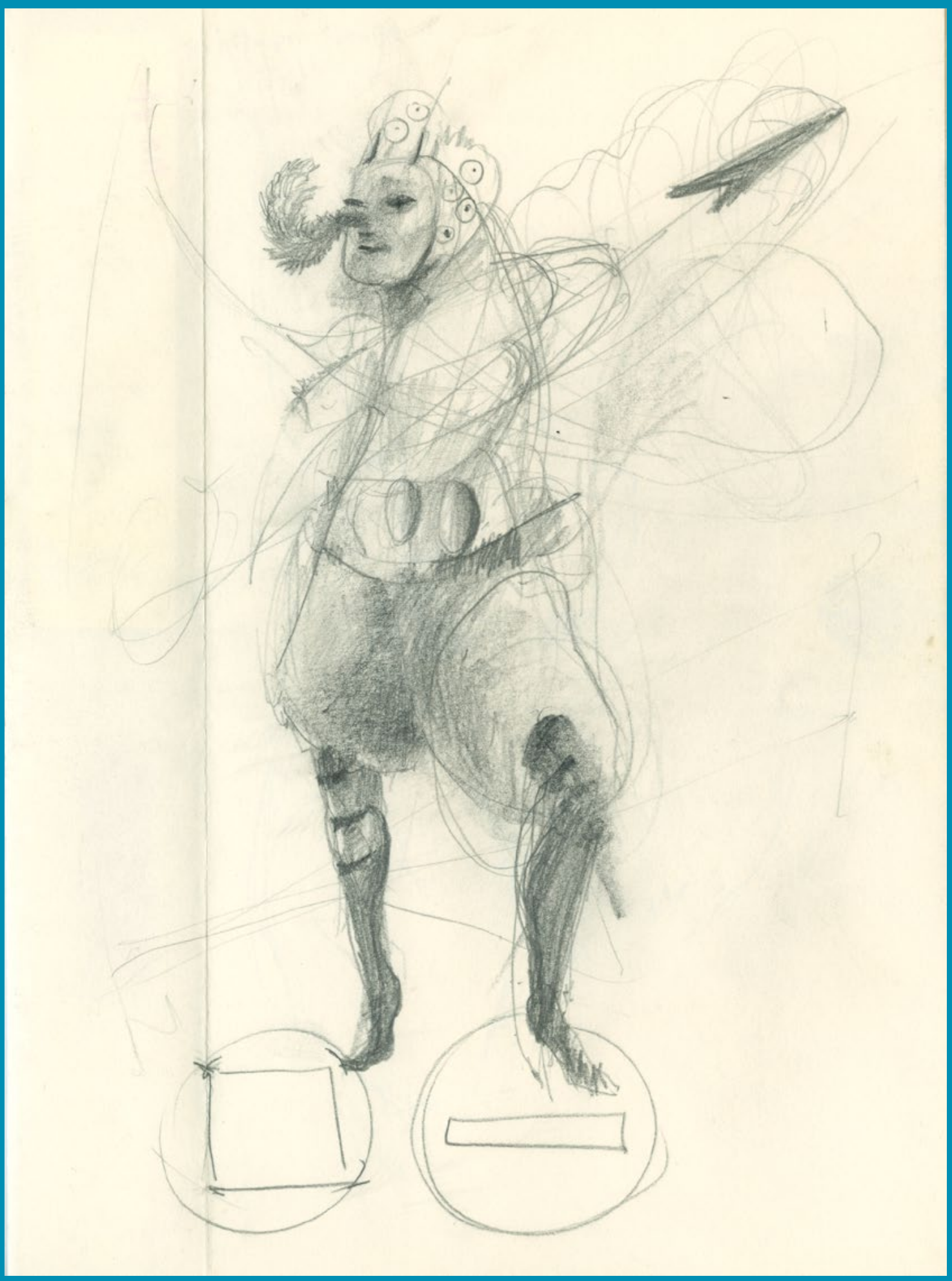

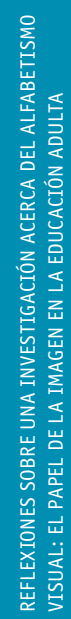




\section{ANTECEDENTES, TERMINOLOGÍA Y LITERATURA}

\section{ALFABETISMO Y ALFABETIZACIÓN}

ES IMPORTANTE clarificar que, aunque la palabra en inglés literacy puede ser traducida al español como «alfabetismo» o «alfabetización», esta investigación se centra en el concepto de alfabetismo. Literacy en inglés se refiere tradicionalmente a la capacidad y destreza que una persona posee de leer y escribir, la cual la califica como «alfabeta» (Rodríguez Gallardo 2007). Así mismo, el Diccionario de la Real Academia Española define "alfabetismo» como «conocimiento básico de lectura y escritura» (Real Academia Española 2018a), mientras que «alfabetización»es entendida como «la acción y efecto de alfabetizar» (Real Academia Española 2018b). En el ámbito educativo, la alfabetización también incluye el proceso de adquisición de lectura y escritura por el que pasa una persona, no solo las acciones de quien enseña dichas habilidades.

Cabe destacar que hoy en día el término alfabetismo se utiliza en muchas disciplinas y áreas de conocimiento, como se ha mencionado anteriormente, para indicar que una persona posee la capacidad de operar/ actuar/ funcionar en cada campo específico. Por ejemplo, el concepto de «alfabetismo informativo» se emplea para expresar que se puede localizar y aplicar información de manera independiente, y el alfabetismo computacional denuncia que se cuenta con los conocimientos necesarios para utilizar efectivamente computadores y tecnologías asociadas (Rodríguez Gallardo 2007). 


\section{FORMACIÓN PROFESIONAL,}

\section{INVESTIGACIÓN Y CURRÍCULO}

ES IMPORTANTE destacar que para establecer conexiones entre el entendimiento del concepto específico de alfabetismo visual de los 15 participantes, su formación profesional y sus prácticas pedagógicas, se les preguntó sobre su nivel de educación y su entrenamiento/formación pedagógica para ser profesores de inglés de adultos. De hecho, todos los participantes habían sido entrenados en docencia. Sin embargo, dicho entrenamiento variaba en duración e intensidad. Algunos de los profesores habían tomado un curso de ocho semanas llamado CELTA (Certificate in English Language Teaching to Adults o certificado de enseñanza del idioma inglés para adultos) (Cambridge Assessment English 2017), y otros habían estudiado licenciaturas y maestrías en educación.

En la práctica, todos los profesores habían enseñado varios niveles de inglés - desde los más básicos hasta los más avanzados-. Lo interesante es que todos con excepción de uno, independientemente de qué curso hubieran tomado, dijeron que hasta el momento de la entrevista para esta investigación nunca habían estudiado el tema del alfabetismo visual. Algunos aclararon que lo que sus instructores les habían enseñado es que las imágenes eran valiosas herramientas para fomentar la lectura, la escritura y la producción oral. Esto se ve reflejado en el currículo de los programas de enseñanza de inglés para adultos. La educadora e investigadora de alfabetismo adulto Helen de Silva Joyce (2014) denuncia que en Australia, a pesar de que el currículo de los programas de inglés que el Gobierno ofrece $a$ inmigrantes y refugiados requiere que los profesores fomenten el desarrollo del alfabetismo visual, esto no ocurre en forma sistemática en la práctica. Esto se debe probablemente a la carencia de instrucción en alfabetismo visual para profesores. En el sector de cursos preuniversitarios para estudiantes extranjeros la situación es similar. Debido a que no hay un currículo prescrito para los tantos centros de enseñanza de inglés en el país, es casi imposible determinar hasta qué punto el alfabetismo visual está presente. 


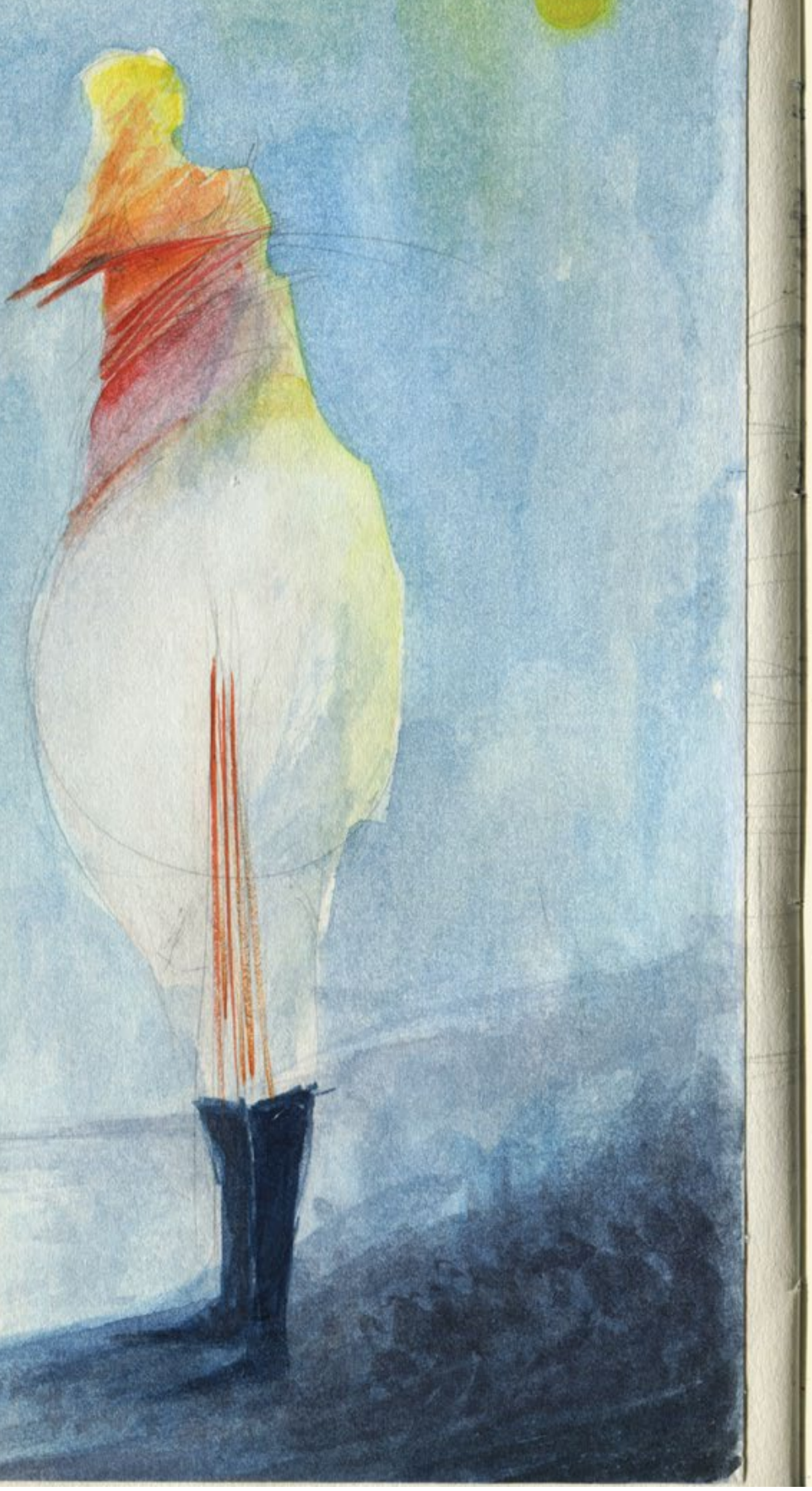

Además de la aparente carencia de instrucción en alfabetismo visual en programas educativos tanto para estudiantes como para profesores de inglés para adultos, esta tampoco parece ser un área de investigación de gran interés en Australia. De acuerdo con publicaciones investigativas de alto perfil a nivel internacional como TESOL Quarterly (revista académica trimestral sobre enseñanza de inglés para hablantes de otros idiomas) y The English Australia Journal (la revista para profesores de inglés en Australia), los educadores e investigadores sobre la enseñanza de inglés continúan enfocándose en temas que han sido tradicionalmente considerados de mayor prioridad por sus gremios profesionales. Estos temas incluyen la escritura para fines académicos, lectura, audición y pronunciación (English Australia 2016). Asimismo, autores como Borg (2013), Burns (2014), Korthagen (2007) y Richards y Farrell (2005) afirman que debido a las exigencias de su trabajo, los profesores de inglés generalmente no cuentan con el tiempo ni interés para mantenerse informados en la última investigación en su campo, a menos que sea un requisito específico de su empleador o por motivos personales, como estudios de posgrado. 


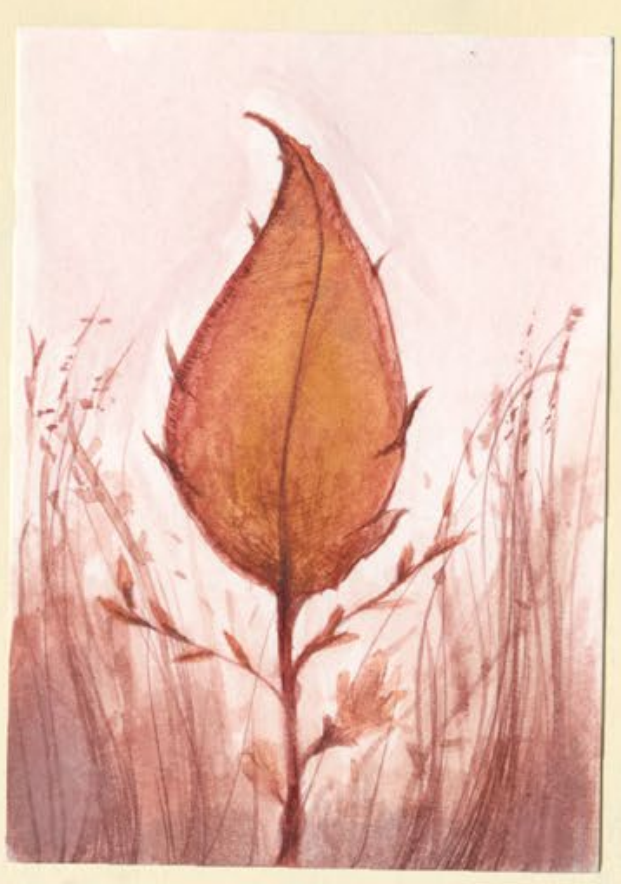

LOS RESULTADOS de esta investigación conducen a tres conclusiones básicas. En primer lugar, es claro que los profesores de inglés para adultos que contribuyeron al estudio acostumbran a usar imágenes en sus pedagogías.

Sin embargo, el papel que le atribuyen a las imágenes es el de complemento o ayuda en el desarrollo de la lectura, la escritura y/o el de la producción oral. Pit Corder, en su estudio seminal llamado The Visual Element in Language Teaching (El elemento visual en enseñanza de lenguas) (Corder 1966), explica la diferencia entre «hablar sobre imágenes» $y$ «hablar con imágenes». El autor argumenta que hablar sobre imágenes implica simplemente el acto de describirlas, mientras que hablar con imágenes significa producir una respuesta crítica y personal como resultado del proceso de observación e interpretación. Hablar (o escribir) sobre imágenes parece ser una práctica que persiste en el campo de enseñanza de inglés para adultos, debido al gran enfoque que se le da al manejo efectivo de textos escritos y a la fluidez en la producción oral.

El segundo punto expuesto en esta investigación es que el concepto de «alfabetismo visual» no parece tener una posición prominente en las ideologías que guían las prácticas pedagógicas de los profesores participantes. En otras palabras, el alfabetismo visual no es un término que se maneje día a día dentro de su discurso profesional, sus actividades de clase o sus objetivos como educadores. Al ser expuestos a la pregunta: ¿qué entiende usted por alfabetismo visual?, todos los los participantes recurrieron a sus experiencias profesionales enseñando a estudiantes provenientes de diversos orígenes socioculturales. De ahí que sus respuestas incluyeran la idea de que la imagen está conectada intrínsecamente con las experiencias de vida y creencias del observador. 
Esta segunda conclusión nos lleva a un punto final: la carencia de instrucción en alfabetismo visual en programas de formación de profesores de inglés para adultos. La gran mayoría de los participantes declaró no poseer extenso conocimiento en el significado de alfabetismo visual o cómo aplicarlo a su profesión, debido a que su formación como educadores de lengua no incluyó este tema. Numerosos autores, tales como Beauchamp and Thomas (2009), Beijaard, Verloop, and Vermunt (2000), Borg (2006), Richards (2015) y Walkington (2005) sostienen que al mismo nivel de la experiencia laboral, la formación profesional es un pilar fundamental en las pedagogías que desarrollan, adquieren y emplean los educadores. Desde este punto de vista, surge la pregunta: ¿cómo se le puede enseñar el alfabetismo visual a los estudiantes de inglés, si sus profesores no están versados/instruidos en dicho concepto, ni tampoco en el uso de estrategias para enseñarlo ni en prácticas que conduzcan a su desarrollo?

Mis recomendaciones son simples. Si la información en el mundo que habitamos se mueve hoy en día en gran parte en forma visual, la enseñanza de cómo entender, interpretar y responder a la imagen, así como la habilidad de expresarse visualmente, necesita una posición mucho más prominente en el currículo de educación de inglés para adultos. Para obtener esto debemos partir por la formación de educadores en el área. Así como los cursos vocacionales, las licenciaturas y las maestrías en enseñanza de lengua cubren el desarrollo de las habilidades de lectura, escritura, audición y producción oral, es indispensable dedicarle estudio especializado al concepto de alfabetismo visual y sus aplicaciones pedagógicas. Dicho estudio debe ser basado en la investigación sobre el campo teniendo en cuenta las necesidades específicas de los estudiantes adultos, ya que provienen no solo de diversos orígenes étnicos, lingüísticos, políticos y culturales, sino que poseen diferentes experiencias de vida. Por ende, estos factores deben gobernar los principios, teorías y estrategias que los docentes empleen para enseñarles la comprensión y el uso reflexivo y eficaz de la imagen, y la relación que dichas habilidades tienen con el desarrollo de la lectura, la escritura, la audición y la producción oral.

Si bien esta investigación se realizó en Australia, espero que las conclusiones y mis recomendaciones sobre la importancia del alfabetismo visual puedan ser aplicadas a cursos de inglés para adultos y en programas de preparación de profesores de lenguas sin importar el contexto geográfico. Fundamentalmente, mi intención es la de promover un cambio positivo en la forma en que los educadores vemos, entendemos y usamos la imagen. 
- Association of College and Research Libraries (ACRL). «ACRL Visual Literacy Competency Standards for Higher Education». American Library Association, 2011. http:// www.ala.org/acrl/standards/visualliteracy.

- Atkins, Sarah-Jane. «Constructing visual literacy: An investigation into upper primary teachers' construction of visual literacy teaching» University of Wollongong, 2006.

- Australian Education International. National Standards for ELICOS (English Language Intensive Courses for Overseas Students) Providers and Courses. Edited by Australian Education International, 2011.

- Avgerinou, Maria D. «Towards a visual literacy index». En Exploring the visual future: Art design, science \& technology, editado por R. E. Griffin, V. S. Villiams y L. Jung, 17-26. Loretto, PA: IVLA, 2001.

- «Towards a visual literacy index». Journal of Visual Literacy 27, no. 1 (2007), 29-46. https://doi.org/10.1080/237 96529.2007.11674644

- Barton, Georgina. «Unpacking visual literacy for early years learners». Practically Primary 21, no.1 (2016), 6.

- Beauchamp, Catherine, y Lynn Thomas. «Understanding teacher identity: an overview of issues in the literature and implications for teacher education». Cambridge Journal of Education 39, no.2 (2009):175-189. https://doi. org/10.1080/03057640902902252

- Beijaard, Douwe, Nico Verloop, y Jan D. Vermunt. 2000. «Teachers' perceptions of professional identity: an exploratory study from a personal knowledge perspective» Teaching and Teacher Education 16, no.7 (2000):749-764. http://dx.doi.org/10.1016/S0742-051X(00)00023-8.

- Bennett, Tamryn. «The kaleidoscope of visual poetry: new approaches to visual literacy». English in Australia 46, no.3 (2011):55-67.

- Boche, Benjamin y Megan Henning. «Multimodal Scaffolding in the Secondary English Classroom Curriculum». Journal of Adolescent \& Adult Literacy 58, no.7 (2015):579590. https://doi.org/10.1002/jaal.406

- Borg, Simon. Teaching Research in Language Teaching: A ctitical analysis. Cambridge: Cambridge University Press, 2013.

- Teacher Cognition and Language Education: Research and Practice. Londres: Continuum, 2006.

- Braun, Virginia y Victoria Clarke. «Using thematic analysis in psychology». Qualitative Research in Psychology 3, (2006): 77-101. https://doi.org/10.1191/1478088706qp063oa

- Bundensen, $C$. «English language teaching and testing: Leading the way?». En Making a difference: Australian international education, editado por D. Davis and B.
MacKintosh. Sydney: University of New South Wales Press Ltd, 2011.

- Burns, A. «Systematic inquiry made public': Teacher reports from a national action research program». Research Notes 56 (2014): 4-6.

- Callow, Jon. 2007. Show me: developing a broader view of visual literacy in education. Werrington NSW: University of Western Sydney.

- Cambridge Assessment English. «CELTA (Certificate in Teaching English to Speakers of Other Languages)». 2017. http://www.cambridgeenglish.org/teaching-english/ teaching-qualifications/celta/.

- Carey, Michael y Anne Robertson. «ELT practice in Australia across three sectors: State education, migrant education, and ELICOS». En English Language Education in a Global World: Practices, Issues and Challenges, 147-160. Nova Science Publishers, Inc, 2015.

- Corder, S. Pit. The visual element in language teaching. Londres : Longmans, 1966.

- De Silva Joyce, Helen. Multimodal and visual literacy in the adult language and literacy classroom. Darlinghurst, NSW, Australia: NSW AMES, 2014.

- Debes, Jhon. L. «The loom of visual literacy». Audiovisual Instruction 14, no.8 (1969): 25-27.

- Donaghy, Kieran y Daniel Xerri. «The image in ELT: an introduction». En The image in English language teaching, editado por Kieran Donaghy and Daniel Xerri. Floriana, Malta: ELT Council, Ministry for Education and Employment, 2017.

- ELICOS. 2014. «ELICOS». Recuperado el 31 de marzo 2015. http://www.elicos.com/elicos-standards/.English Australia. 2015. «English Australia: Industry FAQs.». Recuperado el 5 de mayo 2015. https://www.englishaustralia.com.au/ industry-faqs.

- English Australia. 2016. «2016 Action Research in ELICOS Program». Recuperado el 2 de enero de 2017. https://www. englishaustralia.com.au/page. php?id=512.

- Goldstein, E. Bruce. Cognitive Psychology: Connecting Mind, Research, and Everyday Experience (3rd. edition) Wadsworth: Cengage Learning, 2008.

- Goody, Jack. «The Implications of Literacy». En Literacy: An international handbook, editado por Daniel A. Wagner, Richard L. Venezky y Brian B. Street. Boulder, CO: Westview Press, 1999.

- Hall, Stuart. «Cultural studies: two paradigms». Media, Culture \& Society 2, no.1(1980): 57-72. https://doi. org/10.1177/016344378000200106 
- - «The Work of Representation». En Representations, editado por S. Hall. London y Thousand Oaks, CA: Sage, 1996.

- _ _The Emergence of Cultural Studies and the Crisis of the Humanities». The Humanities as Social Technology 53(1990):11-23. https://doi.org/10.2307/778912

- Hoggart, Richard. Contemporary Cultural Studies. CCCS: University of Birmingham, 1969.

- Hyett, Nerida, Amanda Kenny, y Virginia Dickson-Swift. «Methodology or method? A critical review of qualitative case study reports». International Journal of Qualitative Studies on Health and Well-being 9 (2014). https://doi. org/10.3402/qhw.v9.23606

- Kalantzis, M. y B. Cope. Multiliteracies: Literacy learning and the design of social futures. London: Routledge, 2000.

- Kalantzis, Mary, and Bill Cope. «New Learning: Transformational Designs for Pedagogy and Assessment: Multiliteracies». Recuperado el 4 de septiembre de 2014. http://newlearningonline.com/multiliteracies.

- Keddie, Jamie.«Visual Literacy in ELT». British Council/BBC. Recuperado el 9 de mayo de 2014. https://www.teachingenglish.org.uk/article/jamie-keddie-visual-literacy-elt-0.

- Korthagen, F. A. J. «The gap between research and practice revisited». Educational Research and Evaluation 13, no.3 (2007): 303-310. https://doi. org/10.1080/13803610701640235

- Kress, Gunter y Theo van Leewen. Reading Images: The Grammar of Visual Design (2nd ed.). London: Routledge, 2006. https://doi.org/10.4324/9780203619728

- Lankshear, Colin. New literacies: Changing knowledge and classroom learning. Philadelphia, Pa: Open University Press, 2003.

- Martin, S. A history of the AMEP. Sydney: NCELTR, 2000.

- Messaris, Paul. 2012. "Visual “Literacy” in the Digital Age». Review of Communication 12, no.2 (2012):101-117. https:// doi.org/10.1080/15358593.2011.653508

- Nixon, H. y R. Kerin. «The 3D model of I(IT)eracy and the English curriculum». En Literacy in 3D: An integrated perspective in theory and practice, editado por B. Green and C. Beavis, 62-75. Camberwell, VIC: ACER Press, 2012.

- Oskoz, A. y I. Elola. «Digital stories: Bringing multimodal texts to the Spanish writing classroom». ReCALL 28, no.3 (2016): 326-342. https://doi.org/10.1017/S0958344016000094

- Peña, Ernesto y Teresa M. Dobson. «Humanidades digitales y la movilización del conocimiento: el caso de la alfabetización visual». Virtualis: Revista de cultura digital 7 , no.17(2016).
- Real Academia Española. 2018a. «Alfabetismo». Consultado el 13 de mayo de 2018. http://dle.rae.es/?id=1jUoKD3.

- 2018b. «Alfabetización». Consultado el 13 de mayo de 2018. http://dle.rae.es/?id=1jW6YGF.Richards, J. C. y T. S. C Farrell. Professional development for language teachers: Strategies for teacher learning. Cambridge, UK: Cambridge University Press, 2005. https://doi.org/10.1017/ CB09780511667237

- $\quad$ Richards, J.C. Key Issues in Language Teaching. New York: Cambridge University Press, 2015.

- Rizvi, Fazal. «Student mobility and the shifting dynamics of internationalisation». En Making a difference: Australian international education, editado por D. Davis and B. MacKintosh. Sydney: University of New South Wales Press Ltd., 2011.

- Rodríguez Gallardo, Adolfo. «Definiendo la lectura, el alfabetismo y otros conceptos relacionados (Defining reading, literacy and other related concepts)». Investigación bibliotecológica 21, no.42(2007):143-175. https://doi. org/10.22201/iibi.0187358xp.2007.42.4122

- Sharifian, Farzad. «Globalisation and developing metacultural competence in learning English as an International Language». Multilingual Education 3, no.1(2013):1-11. https://doi.org/10.1186/2191-5059-3-7

- Stake, R. E. The art of case study research. Thousand Oaks, CA: Sage, 1995.

- Walkington, Jackie. «Becoming a teacher: encouraging development of teacher identity through reflective practice». Asia-Pacific Journal of Teacher Education 33, no.1(2005): 53-64. https://doi.org/10.1080/1359866052000341124

- Walsh, M. «Multimodal literacy: What does it mean for classroom practice?». Australian Journal of Language and Literacy 33, no.3 (2010): 211-239.

- Wolcott, H. Transforming qualitative data: Description, analysis, and interpretation. Thousand Oaks, CA: Sage, 1994.

- Yin, Robert K. Case Study Research: Design and Methods. California: SAGE Publications, 2009. 